\title{
Bilateral Investigation of the Anatomical Relationships of the External Branch of the Superior Laryngeal Nerve and Superior Thyroid Artery, and also the Recurrent laryngeal Nerve and Inferior thyroid Artery
}

\author{
By \\ Mine POYRAZ, Ph.D. and Engin ÇAlgüNER, Ph.D. \\ Gazi University School of Medicine, Department of Anatomy, Ankara, Turkey \\ - Received for Publication, March 20, 2000
}

Key Words: External branch of superior laryngeal nerve, Superior thyroid artery, Recurrent laryngeal nerve, Inferior thyroid artery, Relationship

\begin{abstract}
Summary: The relationships of both the external branch of superior laryngeal nerve with the superior thyroidal artery and the recurrent laryngeal nerve with the inferior thyroidal artery were examined on the fixed cadavers of 4 adult women and 26 adult men.

A total of 32 external branches of superior laryngeal nerve, 16 on each side, were dissected. When left and right sides were assessed alltogether, $71.9 \%$ were medial to the artery while $28.1 \%$ were in between the branches. No nerve was found to be lateral to the artery. Thus the type in which the nerve is exposed to surgical trauma was found to be present in $\mathbf{2 8 . 1 \%}$ of the cases. Only 12 of the cadavers could be assessed for symmetry and three fourths were found to have bilaterally symmetric relationship.

A total of 52 Recurrent Laryngeal Nerves, 27 on the left and 25 on the right side were dissected. When bilateral symmetry was assessed in 21 cadavers, one third of the Recurrent Laryngeal Nerves were found to be bilaterally symmetrical. Inferior Thyroidal Artery was missing in 4 sides; bilaterally in one cadaver and unilaterally in 2 cadavers. Thus, artery-nerve relationship was assessed on 48 sides, 25 on the left and 23 on the right. On the right, $39.2 \%$ were in between the branches while $30.4 \%$ were anterior to the artery and $30.4 \%$ were posterior. On the left, $52 \%$ were in between the branches whereas $44 \%$ were posterior and $4 \%$ was anterior to the artery. Thus the position of the nerve in between the branches had the highest incidence while the anterior position had the lowest, the differences being statistically insignificant.
\end{abstract}

It is a well known fact that injury to superior laryngeal and recurrent laryngeal nerves during both carotid endarterectomies and surgical approaches to thyroid and/or parathyroid gland(s) may result in paralysis of one or both of these nerves (Durham and Harrison, 1964; Kambic et al., 1984; Martensson and Terrins, 1985; Lipton et al., 1988). In thyroid operations, it is essential to preserve the parathyroid glands, superior laryngeal nerve and recurrent laryngeal nerve intact (Lore, 1980). However, anatomical variations in one or both of these nerves may result in inadvertent injury and cause severe difficulties in respiration and phonation (Lahey, 1944; Moran and Castro, 1951; Durham and Harrison, 1964; Moosman and Deweese, 1968).
Vocal cord paralysis due to bi and/or unilateral lesions of the recurrent laryngeal nerve is a highly common complication and may also cause serious problems. Lesions of superior laryngeal nerve are also frequent during thyroid surgery but with less dramatic manifestations (Kambic et al., 1984: Martensson and Terrins, 1985). The close relationship of superior laryngeal nerve to superior thyroid artery and superior thyroid vein; of recurrent laryngeal nerve to inferior thyroid artery and inferior thyroid vein are both very important, and good care should be taken during thyroid surgery which may necessitate ligation of the vessels (Moran and Castro, 1951; Hunt, 1961; Moosman and Deweese. 1968; Kambic et al., 1984; Friedman and Toriumi. 1986). The external branch of the superior laryn-

Correspondance to: Prof. Engin ÇALGÜNER, Gazi Üniversitesi Tıp Fakültesi, Anatomi Anabilim Dah, 06500 Beşevler. Ankara. Turkey 
geal nerve passes nearer to the superior thyroidal artery and superior thyroidal vein than the internal branch, and thus is more exposed to surgical trauma during the ligation of the upper pole of the gland (Clader et al., 1957; Hunt, 1961; Durham and Harrison, 1964). Damage to the external branch of the superior laryngeal nerve results in various degrees of paralysis depending upon the severity of lesions and may lead to hoarseness, weakness and decreased control over the pitch of the voice; giving rise to many social and professional problems (Moran and Castro, 1951; Moosman and Deweese, 1968; Lore et al., 1977). The recurrent laryngeal nerve may have various relationships to the arteries, rendering it vulnerable to surgical trauma; thus the surgeon must have both a detailed knowledge of the anatomical variations of laryngeal vesselsnerves with their interrelationships and a meticulous technique to be applied throughout the dissection of the thyroid gland (Bowden, 1955; Clader et al., 1957; Hunt, 1961; Durham and Harrison, 1964; Kambic et al., 1984; Cernea et al., 1992; Harris, 1992; Lekacos et al., 1992).

Our aim was to disclose both the variations and the normal anatomy of vessel-nerve relationships so as to diminish the intraoperative nerve injuries.

\section{Materials and Methods}

The fixed cadavers of 4 women and 26 men were used. The relationships of both the external branch of superior laryngeal nerve with the superior thyroidal artery and recurrent laryngeal nerve with the inferior thyroidal artery were examined. By using routine anatomical dissection techniques; the vagus nerve was identified and the external branch of superior laryngeal nerve was followed in its course to the inferior constrictor muscle, in close relationship with superior thyroidal artery exposed for closer study. The relationship between superior laryngeal nerve and superior thyroidal artery were classified as follows: (Lennquist et al., 1987)

Type A: Nerve, medial to the artery and its branches

Type B: Nerve, lateral to the artery and its branches

Type C: Nerve, in between the branches of the artery (Fig. 1).

By pulling forward the inferior lobes of thyroid gland, the recurrent laryngeal nerve was identified in the groove between trachea and oesophagus on each side, followed in its course along the lower margin of inferior pharyngeal constrictor muscle, exposed for closer study. The relationship between recurrent laryngeal nerve and inferior thyroidal ar-

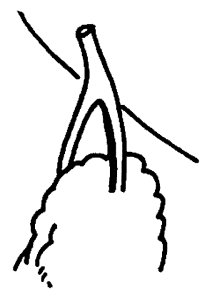

A

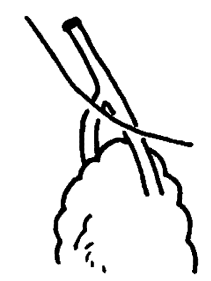

B

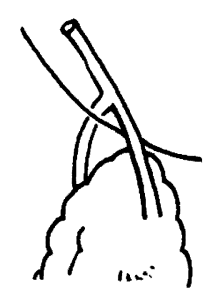

$\mathrm{C}$
Fig. 1. Types of the relationship between the external branch of superior laryngeal nerve and superior thyroidal artery: Type A: Nerve, medial to the artery; Type B: Nerve, lateral to the artery and; Type C: Nerve, in between the branches of the artery.

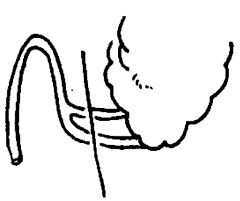

A

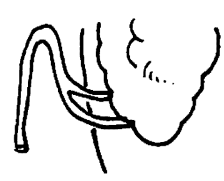

B

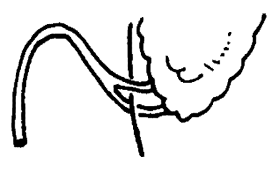

C
Fig. 2. Types of the relationship between recurrent laryngeal nerve and inferior thyroidal artery: Type A: Nerve, ante rior to the artery; Type B: Nerve, posterior to the artery; and Type C: Nerve, in between the branches of the artery.

tery was classified as follows (Bowden, 1955; Clader et al., 1957; Kratz, 1973; Al-Salihi and Dabbagh, 1989; Hirata, 1992; Lekacos et al., 1992)

Type A: Nerve, anterior to the artery and its branches

Type B: Nerve, posterior to the artery and its branches

Type C: Nerve, in between the branches of the artery (Fig. 2).

In each case, the artery and nerve relationships were evaluated bilaterally using Fisher's exact Khi square test. The bilateral asymmetry or symmetry of the artery-nerve relationship were also evaluated and these relationships were photographed.

\section{Results}

Correlation of the Relationships Between Superior Thyroidal Artery and External Branches of Superior Laryngeal Nerve

A total of 32 superior laryngeal nerves, 16 on each side, were dissected. The relationship between superior laryngeal nerve and superior thyroidal artery was classified as shown in Table 1 . 
No nerve was found to be lateral to the artery (Type B). Thus the type (Type C) in which the nerve is exposed to surgical trauma was found to be present in $28.1 \%$ of the cases (Figs. 3, 4; Table 1).

Only 12 of the cadavers could be assessed for symmetry. 9 out of these $(75 \%)$ were found to have bilaterally symmetric relationship while $3(25 \%)$ were asymmetrical.

Correlation of the Relationships Between Inferior Thyroidal Artery and Recurrent Laryngeal Nerve

A total of 52 recurrent laryngeal nerves, 27 on the left and 25 on the right side were dissected. Inferior thyroidal artery was missing in 4 sides; bilaterally in one cadaver and unilaterally in 2 cadavers. Thus, artery-nerve relationship was assessed on 48 sides, 25 on the left and 23 on the right. No nonrecurrent laryngeal nerve was found. The relationship between recurrent laryngeal nerve and inferior thyroidal artery was classified as shown in Table 2.

On the left, location of the nerve anterior to the artery had the lowest possibility while its location in between the branches had the highest possibility and posterior location close to this possibility.

On the right, possibility of finding the nerve anterior or posterior to the artery were the same while its position in between the branches was also close to this possibility, the differences being statistically insignificant.

When left and right sides were assessed altogether; the position of the nerve in between the branches had the highest incidence while the anterior position had the lowest (Figs. 5, 6, 7; Table 2).

When the bilateral symmetry was assessed in 21 cadavers, 7 were found to be symmetrical $(33.3 \%)$ while 14 were asymmetrical (66.6\%). Bilaterally symmetric position of the nerve anterior to the artery was not observed, while bilaterally symmetrical position of the nerve either posterior to the artery or in between the branches had the same incidences.

\section{Discussion}

Paralysis of the laryngeal nerve is very important both for the layman from the point of being able to speak without embarrassment and for the professional from the point of being able to sing or lecture with success (Hunt, 1961). The close relationships of superior laryngeal nerve to superior thyroidal artery and of recurrent laryngeal nerve to inferior thyroidal artery or inferior thyroidal vein may give rise to injury of the nerves throughout the thyroid operations if the necessary precautions are not held (Hunt, 1961; Moosman and Deweese, 1968; Lore et al., 1977).

It is a widely held belief that; if the recurrent laryngeal nerve is exposed entirely, then it may be protected in a better way (Lahey, 1944; Lore et al., 1977; Harris, 1992; Lekacos et al., 1992). Total exposure of the recurrent laryngeal nerve truncus

Table 1. Percentages of various types of the relationship between the external branch of the superior laryngeal nerve and superior thyroidal artery $(p>0.01)$

\begin{tabular}{|c|c|c|c|c|}
\hline & $\begin{array}{l}\text { Dissection } \\
\text { number }\end{array}$ & $\begin{array}{l}\text { Medial } \\
\text { (Type A) }\end{array}$ & $\begin{array}{l}\text { Lateral } \\
\text { (Type B) }\end{array}$ & $\begin{array}{l}\text { Between the } \\
\text { Branches } \\
\text { (Type C) }\end{array}$ \\
\hline Left & 16 & $12(75 \%)$ & - & $4(25 \%)$ \\
\hline Right & 16 & $11(68.8 \%)$ & - & $5(31.2 \%)$ \\
\hline Total & 32 & $23(71.9 \%)$ & - & $9(28.1 \%)$ \\
\hline
\end{tabular}

Table 2. Percentages of various types of the relationship between the recurrent laryngeal nerve and inferior thyroidal artery $(p>0.01)$

\begin{tabular}{|c|c|c|c|c|}
\hline & $\begin{array}{l}\text { Dissection } \\
\text { number }\end{array}$ & $\begin{array}{l}\text { Anterior } \\
\text { (Type A) }\end{array}$ & $\begin{array}{l}\text { Posterior } \\
\text { (Type B) }\end{array}$ & $\begin{array}{l}\text { Between the } \\
\text { Branches } \\
\text { (Type C) }\end{array}$ \\
\hline Left & 25 & $1(4 \%)$ & $11(44 \%)$ & $13(52 \%)$ \\
\hline Right & 23 & $7(30.4 \%)$ & $7(30.4 \%)$ & $9(39.2 \%)$ \\
\hline Total & 48 & $8(16.7 \%)$ & $18(37.5 \%)$ & $22(45.8 \%)$ \\
\hline
\end{tabular}


both makes easier the protection of its branches and also reveals whether its anatomic position is normal or abnormal. When the truncus is missing; one must consider the possibility of a nonrecurrent laryngeal nerve (Lahey, 1944; Hunt, 1961; Lore et al., 1977). Surgeons generally do not expose the external branch of superior laryngeal nerve since it is technically more difficult than the recurrent laryngeal nerve (Hunt, 1961; Kambic ei al., 1984). For this aim, the vascular pedicle is cut near to the thyroid gland while the upper pole of the gland is being retracted inferiorly during surgery; and no injury to the external branch of superior laryngeal nerve has been reported (Harris, 1992). Friedman et al. (1986) found the incidence of nonrecurrent laryngeal nerve to be $0.9 \%$ while Lecakos et al. (1992) found it to be $0.53 \%$ and Sanders et al. (1983) $0.7 \%$ among 1000 thyroidectomy cases. The surgeon who is unaware of the nonrecurrent laryngeal nerve can ignore the nerve during the artery ligation (Lahey, 1944; Bowden, 1955; Hunt, 1961; Lore et al., 1977). In our study, no nonrecurrent laryngeal nerve was found to be present among the 52 dissected sides.

Some authors have used electrophysiological monitoring of the intrinsic laryngeal muscles technique in order to identify the external branch of superior laryngeal nerve or the recurrent laryngeal nerve (Lipton et al., 1988; Rice and Cone-Wesson, 1991; Eisele and Goldstone, 1991). However, detailed knowledge of all the possible anatomical variations of the laryngeal nerves is essential for its routine identification and exposure without any injury (Bowden, 1955; Clader et al., 1957; Durham and Harrison, 1964; Kambic et al., 1984; Al-Salihi and Dabbagh, 1989; Cernea et al., 1992; Harris, 1992; Lekacos et al., 1992).

The Interrelationship Between Superior Laryngeal Nerve and Superior Thyroidal Artery

Clader et al. (1957) found external branches of superior laryngeal nerve under surgical injury risk in $68 \%$ of the cases; under questionable risk in $12 \%$ of the cases and under no risk in $20 \%$ of the cases; according to its distance from the ligature location.
Cernea (1992) found the injury rate to be $20 \%$ according to the distance of the nerve to the upper pole of the gland, while Lennquist (1987) found this risk to be present in $18 \%$ of the cases; the same ratio to be $28.1 \%$ in our series. When compared to the data of the investigators who had studied the relationship between the superior laryngeal nerve and superior thyroid artery; our results were found to be in accordance to the data in Lennquist's series (Table 3).

Cernea et al. (1992) found $47 \%$ of symmetry and $53 \%$ of asymmetry while Durham and Harrison (1964) found symmetry in $1 / 3$ of the cases. These values revealed the different injury risks for each side during bilateral thyroidectomies (Cernea et al., 1992).

\section{The Interrelationship Between Recurrent Laryngeal} Nerve and Inferior Thyroidal Artery

The recurrent laryngeal nerve may be anterior, posterior to the artery or may be lying in between the arterial branches (Bowden, 1955; Wade and Cardiff, 1955; Clader et al., 1957; Kratz, 1973; Lore, 1980; Al-Salihi and Dabbagh, 1989; Hirata, 1992; Lekacos et al., 1992; Salama and Mcgrath, 1992).

In our study of the right side, the possibility of the nerve being in between the arterial branches $(39.2 \%)$ was the highest. This finding is in conflict with the results of only Lekacos et al. (1992) who found the highest possibility in the posterior position. In our study, the anterior and posterior position of the artery was found to be of equal possibility; in accordance with the findings of Kratz (1973) and Bowden (1955) (Table 4). Wade (1955) and Clader (1957) found the nerve mostly to be in between the arterial branches rather than being posterior, and anterior position had the lowest incidence. Salama (1992) found the nerve posterior to the artery or in between the branches with the equal incidences $(40.3 \%)$ while the anterior position being the least possible (19.4\%). Al Salihi (1989) found the nerve to be in between the branches $(36.8 \%)$, anterior to the artery $(34 \%)$ or posterior $(29.2 \%)$ of the artery. Thus our findings more or less resemble the other series in the literature.

Table 3. Comparison of the data from the medical literature with our data; concerning the percentages of various types of the relationship between the external branch of the superior laryngeal nerve and superior thyroidal artery

\begin{tabular}{lclll}
\hline AUTHOR & $\begin{array}{l}\text { Dissection } \\
\text { number }\end{array}$ & $\begin{array}{l}\text { Medial } \\
\text { (Type A) }\end{array}$ & $\begin{array}{l}\text { Lateral } \\
\text { (Type B) }\end{array}$ & $\begin{array}{l}\text { Between the } \\
\text { Branches } \\
\text { (Type C) }\end{array}$ \\
\hline $\begin{array}{l}\text { Lennquist } \text { et al. }(1987) \\
\text { Çalgüner } \text { et al. }\end{array}$ & 50 & $\begin{array}{l}41(82 \%) \\
23(71.9 \%)\end{array}$ & $\begin{array}{l}2(4 \%) \\
-\end{array}$ & $\begin{array}{l}7(14 \%) \\
9(28.1 \%)\end{array}$ \\
\hline
\end{tabular}


Table 4. Comparison of the data from the medical literature with our data; concerning the percentages of various types of the relationship between the reccurrent laryngeal nerve and inferior thyroidal artery on the right side

\begin{tabular}{lrrrr}
\hline AUTHOR & $\begin{array}{l}\text { Dissection } \\
\text { number }\end{array}$ & $\begin{array}{l}\text { Anterior } \\
\text { (Type A) }\end{array}$ & $\begin{array}{l}\text { Posterior } \\
\text { (Type B) }\end{array}$ & $\begin{array}{l}\text { Between the } \\
\text { Branches } \\
\text { (Type C) }\end{array}$ \\
\hline Lekacos et al. $(1992)$ & 109 & $19(17.4 \%)$ & $52(47.7 \%)$ & $38(34.9 \%)$ \\
Al-Salihi and Dabbagh (1989) & 106 & $36(34.0 \%)$ & $31(29.2 \%)$ & $39(36.8 \%)$ \\
Salama et al. $(1992)$ & 72 & $14(19.4 \%)$ & $29(40.3 \%)$ & $29(40.3 \%)$ \\
Kratz (1973) & 56 & $14(25.0 \%)$ & $16(28.6 \%)$ & $26(46.4 \%)$ \\
Clader et al. $(1957)$ & 48 & $9(18.8 \%)$ & $16(33.3 \%)$ & $23(47.9 \%)$ \\
Wade et al. $(1955)$ & 93 & $16(17.2 \%)$ & $37(39.8 \%)$ & $40(43.0 \%)$ \\
Hirata (1992) & 416 & $135(32.5 \%)$ & $111(26.7 \%)$ & $170(40.9 \%)$ \\
Bowden (1955) & 28 & $8(28.6 \%)$ & $9(32.1 \%)$ & $11(39.3 \%)$ \\
Çalgüner et al. & 23 & $7(30.4 \%)$ & $7(30.4 \%)$ & $9(39.2 \%)$ \\
\hline
\end{tabular}

On the left side, highest incidence of the nerve is found to be to the posterior of the artery; followed by the incidence of being in between the artery branches and the lowest incidence of being anterior. This finding is the same in all series but only Al-Salihi (1989) who found the anterior position being at the second place. Wade et al. (1955) and Hunt (1961) pointed out that the aforementioned highest possibility for the posterior position of the nerve resulted in the lowest surgical risk. In our series, Recurrent laryngeal nerve was found to be in between the artery branches $(52 \%)$; followed by the posterior $(44 \%)$ and the anterior $(4 \%)$ positions (Table 5). Although we found that the position with the highest incidence was in between the branches, there was not a big difference between this incidence and the following incidence of the posterior position; rendering our series parallel to other authors' findings.

When the two sides are assessed altogether; most of the authors have found the nerve being posterior to the artery ( $49.2 \%$ ) followed by being in between the branches $(33.5 \%)$ and with the least possibility being to the anterior of the artery $(17.3 \%)$. In our series, the highest possibility was being in between the branches $(45.8 \%)$, followed by being to the posterior $(37.5 \%)$ and anterior $(16.7 \%)$ of the artery (Table 6). In the literature; the nerve has been found to be mostly in between the artery branches on the right side and mostly posterior to the artery on the left side whereas in our series the nerve was mostly in between the branches on both sides; all of the differences between right and left sides being statistically insignificant (Tables $4,5,6$ ).

In the literature, 99 cases among 311 were reported to have a symmetrical position (Bowden, 1955). In accordance we found 7 cases out of 21 to be symmetrical.

\section{Conclusion}

In conclusion, the commonest position of the external branch of superior laryngeal nerve being

Table 5. Comparison of the data from the medical literature with our data; concerning the percentages of various types of the relationship between the reccurrent laryngeal nerve and inferior thyroidal artery on the left side

\begin{tabular}{lcccc}
\hline AUTHOR & $\begin{array}{c}\text { Dissection } \\
\text { Number }\end{array}$ & $\begin{array}{l}\text { Anterior } \\
\text { (Type A) }\end{array}$ & $\begin{array}{l}\text { Posterior } \\
\text { (Type B) }\end{array}$ & $\begin{array}{l}\text { Between the } \\
\text { Branches } \\
\text { (Type C) }\end{array}$ \\
\hline Lekacos et al. $(1992)$ & 82 & $12(14.6 \%)$ & $45(54.9 \%)$ & $25(30.5 \%)$ \\
Salama et al. $(1992)$ & 72 & $14(19.4 \%)$ & $35(48.6 \%)$ & $23(31.9 \%)$ \\
Wade et al. $(1955)$ & 92 & $5(5.4 \%)$ & $58(63.0 \%)$ & $29(31.5 \%)$ \\
Hirata (1992) & 368 & $18(4.9 \%)$ & $242(65.8 \%)$ & $108(29.3 \%)$ \\
Kratz (1973) & 52 & $8(15.4 \%)$ & $26(50.0 \%)$ & $18(34.6 \%)$ \\
Bowden (1955) & 27 & $3(11.1 \%)$ & $15(55.6 \%)$ & $9(33.3 \%)$ \\
Al-Salihi and Dabbagh (1989) & 106 & $13(12.3 \%)$ & $83(78.3 \%)$ & $10(9.4 \%)$ \\
Clader et al. $(1957)$ & 48 & $1(2.1 \%)$ & $32(66.7 \%)$ & $15(31.3 \%)$ \\
Çalgüner et al. & 25 & $1(4.0 \%)$ & $11(44.0 \%)$ & $13(52.0 \%)$ \\
\hline
\end{tabular}


medial to the superior thyroidal artery had a lower risk whereas the commonest position of recurrent laryngeal nerve being in between the branches of inferior thyroidal artery had a higher surgical risk. The superior laryngeal nerve position was found to be mostly symmetrical between the right and left sides while the recurrent laryngeal nerve position was mostly asymmetrical.

Table 6. Comparison of the data from the medical literature with our data; concerning the percentages of various types of the relationship between the reccurrent laryngeal nerve and inferior thyroidal artery assessed bilaterally

\begin{tabular}{|c|c|c|c|c|c|c|c|}
\hline \multirow[t]{2}{*}{ AUTHOR } & \multirow{2}{*}{$\begin{array}{l}\text { Dissection } \\
\text { Number }\end{array}$} & \multicolumn{2}{|l|}{ Variation } & \multirow{2}{*}{$\begin{array}{l}\text { Normal } \\
\text { Nerve } \\
\text { Number }\end{array}$} & \multirow{2}{*}{$\begin{array}{l}\text { Anterior } \\
\text { (Type A) }\end{array}$} & \multirow{2}{*}{$\begin{array}{l}\text { Posterior } \\
\text { (Type B) }\end{array}$} & \multirow{2}{*}{$\begin{array}{l}\text { Between the } \\
\text { Branches } \\
\text { (Type C) }\end{array}$} \\
\hline & & $\begin{array}{l}\text { Nonrecurrent } \\
\text { Right } \\
\text { Laryngeal } \\
\text { Nerve }\end{array}$ & $\begin{array}{l}\text { Absence } \\
\text { of Artery }\end{array}$ & & & & \\
\hline Wade et al. (1955) & 200 & 4 & 11 & 185 & $21(11.4 \%)$ & $95(51.4 \%)$ & $69(37.2 \%)$ \\
\hline Reeve et al. (1969) & 157 & $*$ & 13 & 144 & $23(16 \%)$ & $112(77.8 \%)$ & $9(6.3 \%)$ \\
\hline Hirata (1992) & 784 & $*$ & $*$ & 784 & $153(19.5 \%)$ & $353(45 \%)$ & $278(35.5 \%)$ \\
\hline Lekacos et al. (1992) & 192 & 1 & $*$ & 191 & $31(16.2 \%)$ & $97(50.8 \%)$ & $63(33.0 \%)$ \\
\hline Bowden (1955) & 58 & 1 & 2 & 55 & $11(20 \%)$ & $24(43.6 \%)$ & $20(36.4 \%)$ \\
\hline Clader et al. (1957) & 97 & $*$ & 1 & 96 & $10(10.4 \%)$ & $48(50 \%)$ & $38(39.6 \%)$ \\
\hline Salama et al. (1992) & 144 & $*$ & $*$ & 144 & $28(19.4 \%)$ & $64(44.4 \%)$ & $52(36.1 \%)$ \\
\hline Çalgüner et al. & 52 & - & 4 & 48 & $8(16.7 \%)$ & $18(37.5 \%)$ & $22(45.8 \%)$ \\
\hline Total & 1684 & 6 & 31 & 1647 & $285(17.3 \%)$ & $811(49.2 \%)$ & $551(33.5 \%)$ \\
\hline
\end{tabular}

*: Unspecified.

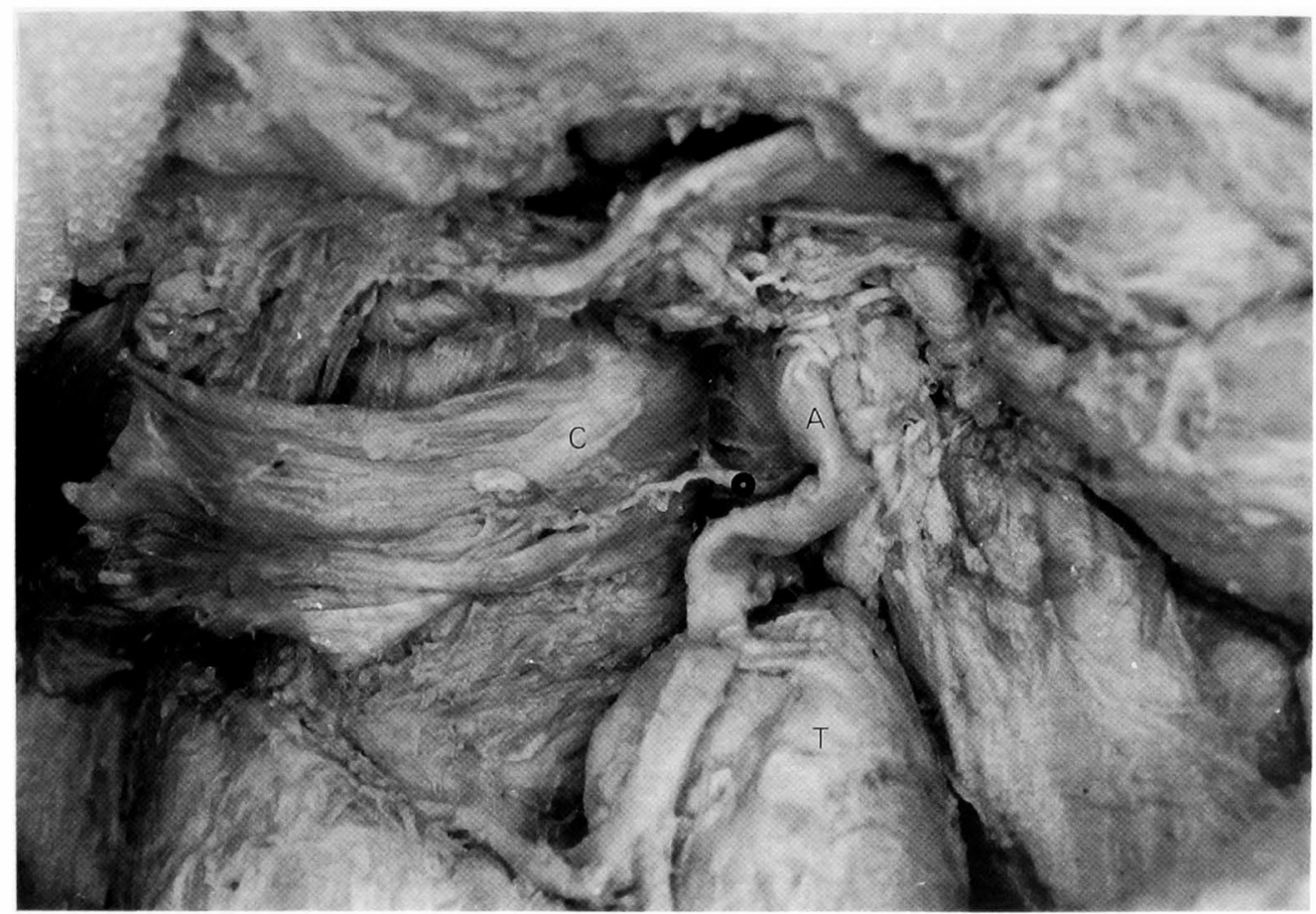

Fig. 3. The external branch of the left superior laryngeal nerve medial to the superior thyroid artery (Type A). A: superior thyroid artery, C: inferior constrictor pharyngeal muscle, *: external branch of the superior laryngeal nerve, T: Upper pole of the thyroid gland. 


\section{References}

1) Al-Salihi AR and AW Dabbagh. Anatomy of the Recurrent Laryngeal Nerve in Normal Iraqis. Acta Anat 1989; 135:245-247.

2) Bowden REM. The Surgical Anatomy of the Recurrent Laryngeal Nerve. Br J Surg 1955; 43:153-163.

3) Cernea CR, AR Ferraz, S Nishio, A Dutra, FC Hojaij and LRM Santos. Surgical Anatomy of the External Branch of the Superior Laryngeal Nerve. Head and Neck 1992; 14:380-383.

4) Clader DN, PW Luter and BT Daniels. A Photographic Study of the Superior and Inferior Laryngeal Nerves and the Superior and Inferior Thyroid Arteries. The Am Surg 1957; 23:609-618.

5) Durham CF and TS Harrison. The Surgical Anatomy of the Superior Laryngeal Nerve. Surg Gynecol Obstet 1964; 118:38-44.

6) Eisele DW and AC Goldstone. Electrophysiologic Identification and Preservation of the Superior Laryngeal Nerve During Thyroid Surgery. Laryngoscope 1991; 101:313-315.
7) Friedman $M$ and DM Toriumi. Functional Identification of the External Laryngeal Nerve During Thyroidectomy, Laryngoscope 1986; 96:1291-1292.

8) Friedman M, DM Toriumi, V Grybauskas and A Katz. Nonrecurrent Laryngeal Nerves and Their Clinical Significance. Laryngoscope 1986: 96:87 90.

9) Harris SC. Thyroid and Parathyroid Surgical Complications. Am J Surg 1992; 163:476-478.

10) Hirata K. Relationship Between the Laryngeal Nerve and the Inferior Thyroid Artery in Japanese. Acta Anat Nippon 1992; 67:634-641.

11) Hunt CJ. The Superior and Inferior Laryngeal Nerve as Related to Thyroid Surgery. Am Surg 1961; 27:548-552.

12) Kambic V, M Zargi and Z Radsel. Topographic anatomy of the external branch of the superior laryngeal nerve. $J$ Laryngol Otol 1984; 98:1121-1124.

13) Kratz RC. The Identification and Protection of the Laryngeal Motor Nerves During Thyroid and Laryngeal Surgery: A New Mikrosurgical Technique. Laryngoscope 1973; 33:59-78.

14) Lahey FH. Exposure of the Recurrent Laryngeal Nerves in

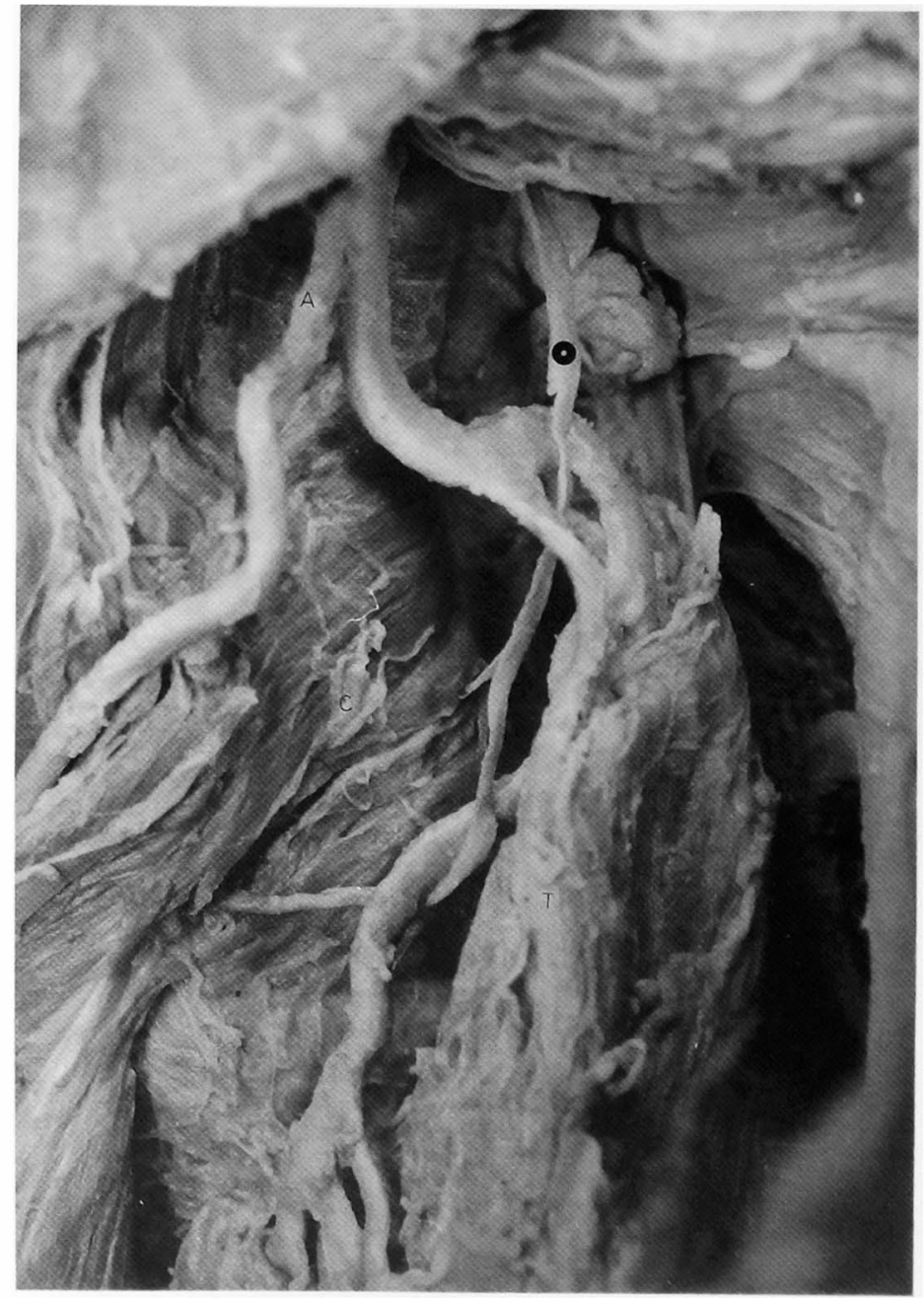

Fig. 4. The external branch of the left superior laryngeal nerve between the branches of the superior thyroid artery (Type C). A: superior thyroid artery, C: inferior constrictor pharyngeal muscle *: external branch of the superior laryngeal nerve. $T$ : Upper pole of the thyroid gland. 
Thyroid Operations. Surg Gynecol Obstet 1944; 78:239-44.

15) Lekacos NL, PJ Tzardis, PG Sfikakis, SD Patoulis and SD Restos. Course of the Recurrent Laryngeal Nerve Relative to the Inferior Thyroid Artery and the Suspensory Ligament of Berry. Int Surg 1992; 77:287-288.

16) Lennquist $S, C$ Cahlin and S Smeds. The Superior Laryngeal Nerve in Thyroid Surgery. Surg 1987; 102(6):999 1008.

17) Lipton RJ, TV McCaffrey and WJ Litchy. Intraoperative Electrophysiologic Monitoring of Laryngeal Muscle During Thyroid Surgery. Laryngoscope 1988; 98:1292-1296.

18) Lore JM, DJ Kim and S Elias. Preservation of the I aryngeal Nerves During Total Thyroid Lobectomy. Ann Otol 1977; 86:777-788.

19) Lore JM. Surgery of the Thyroid Gland. Otolaryngol Clin North Am 1980; 13(1):69-83.

20) Martensson $H$ and $J$ Terrins. Recurrent Laryngeal Nerve Palsy in Thyroid Gland Surgery Related to Operations and
Nerves at Risk. Arch Surg 1985; 120:475-477.

21) Moosman DA and MS Deweese. The External Laryngeal Nerve as Related to Thyroidectomy. Surg Gynecol Obstet 1968; 127:1011-1016.

22) Moran RE and AF Castro. The Superior Laryngeal Nerve in Thyroid Surgery. Ann Surg 1951; 134(6):1018-1021.

23) Rice $\mathrm{DH}$ and $\mathrm{B}$ Cone-Wesson. Intraoperative Recurrent Laryngeal Nerve Monitoring. Otolaryngol Head Neck Surg 1991; 105(3):372-5.

24) Salama $A B$ and $P$ Mcgrath. Recurrent Laryngeal Nerve and the posterior Fascial Attachment of the Thyroid Gland. Aust N Z J Surg 1992; 62:444-449.

25) Sanders G, RY Uyeda and MS Karlan. Nonrecurrent Inferior Laryngeal Nerves and Their Association With a Recurrent Branch. Am J Surg 1983; 146:501-503.

26) Wade JSH and MC Cardiff. Vulnerability of the Recurrent Laryngeal Nerves at Thyroidectomy. Br J Surg 1955; 43:164-8.

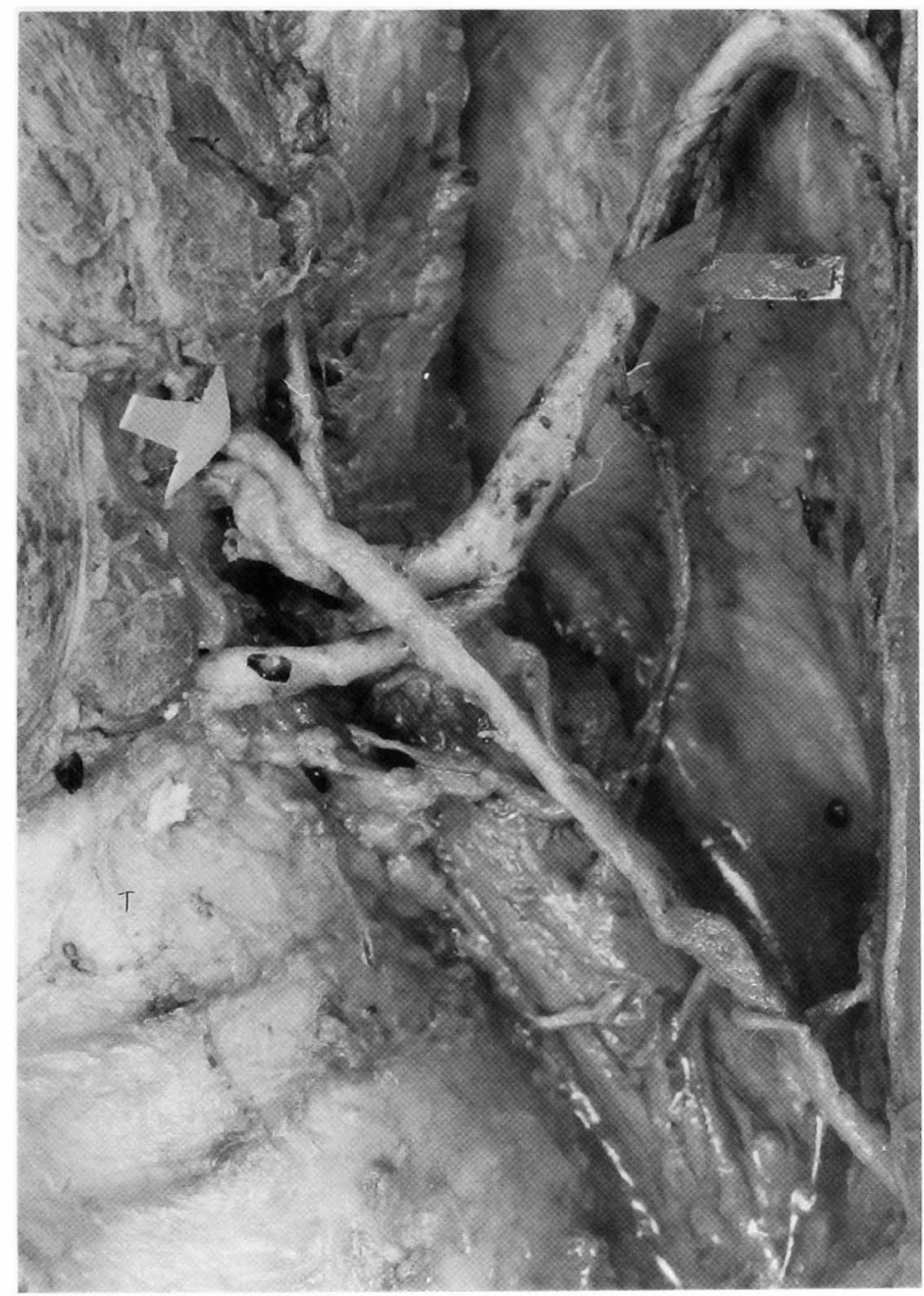

Fig. 5. The left recurrent laryngeal nerve anterior to the inferior thyroid artery (Type A). Arrow on the right: inferior thyroid artery; arrow on the left: recurrent laryngeal nerve; $T$ : trachea. 


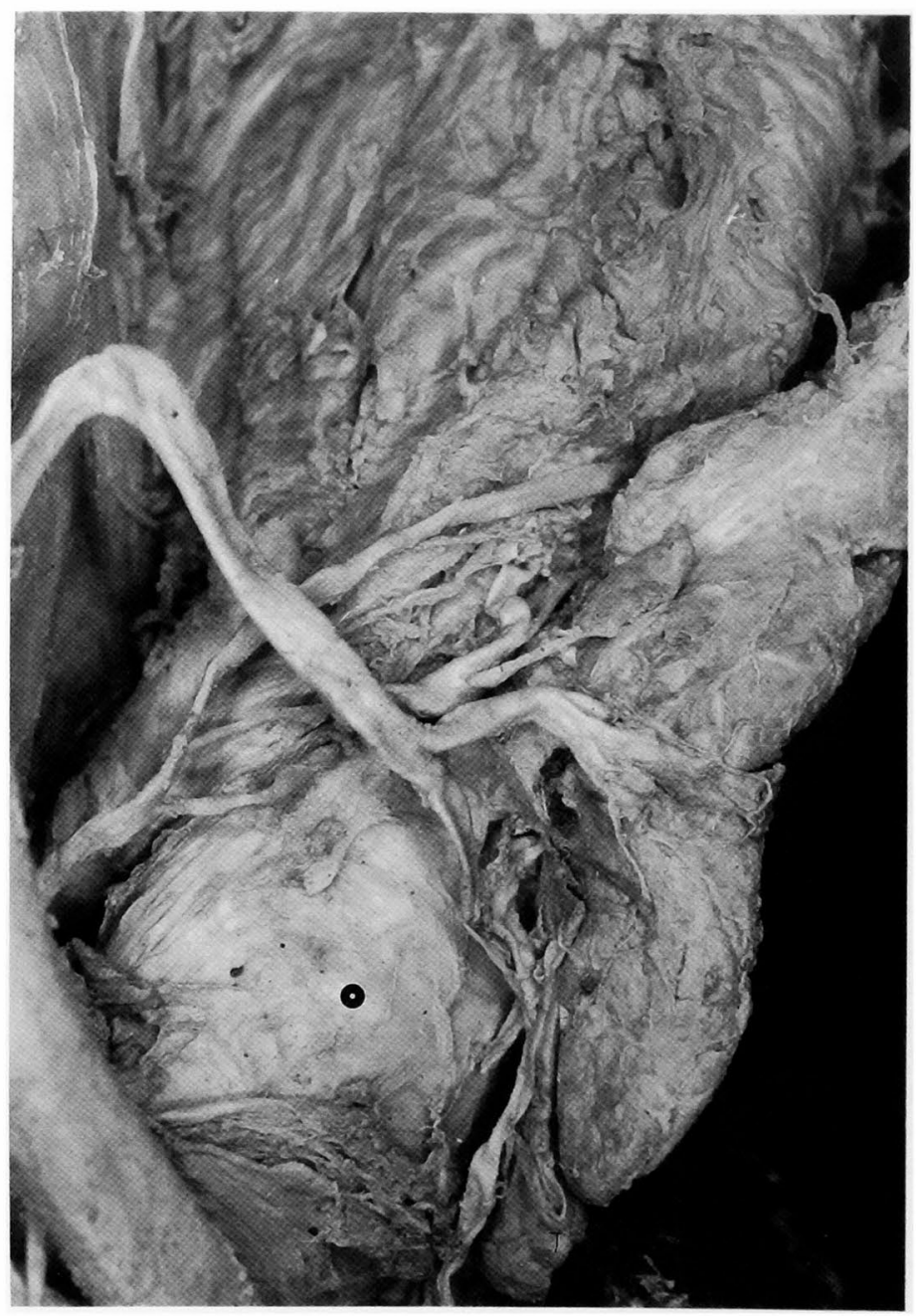

Fig. 6. The right recurrent laryngeal nerve posterior to the inferior thyroid artery (Type B). Arrow on the left: inferior thyroid artery; arrow on the right: recurrent laryngeal nerve, $\mathrm{T}$ : lower pole of the tyroid gland. *: trachea. 


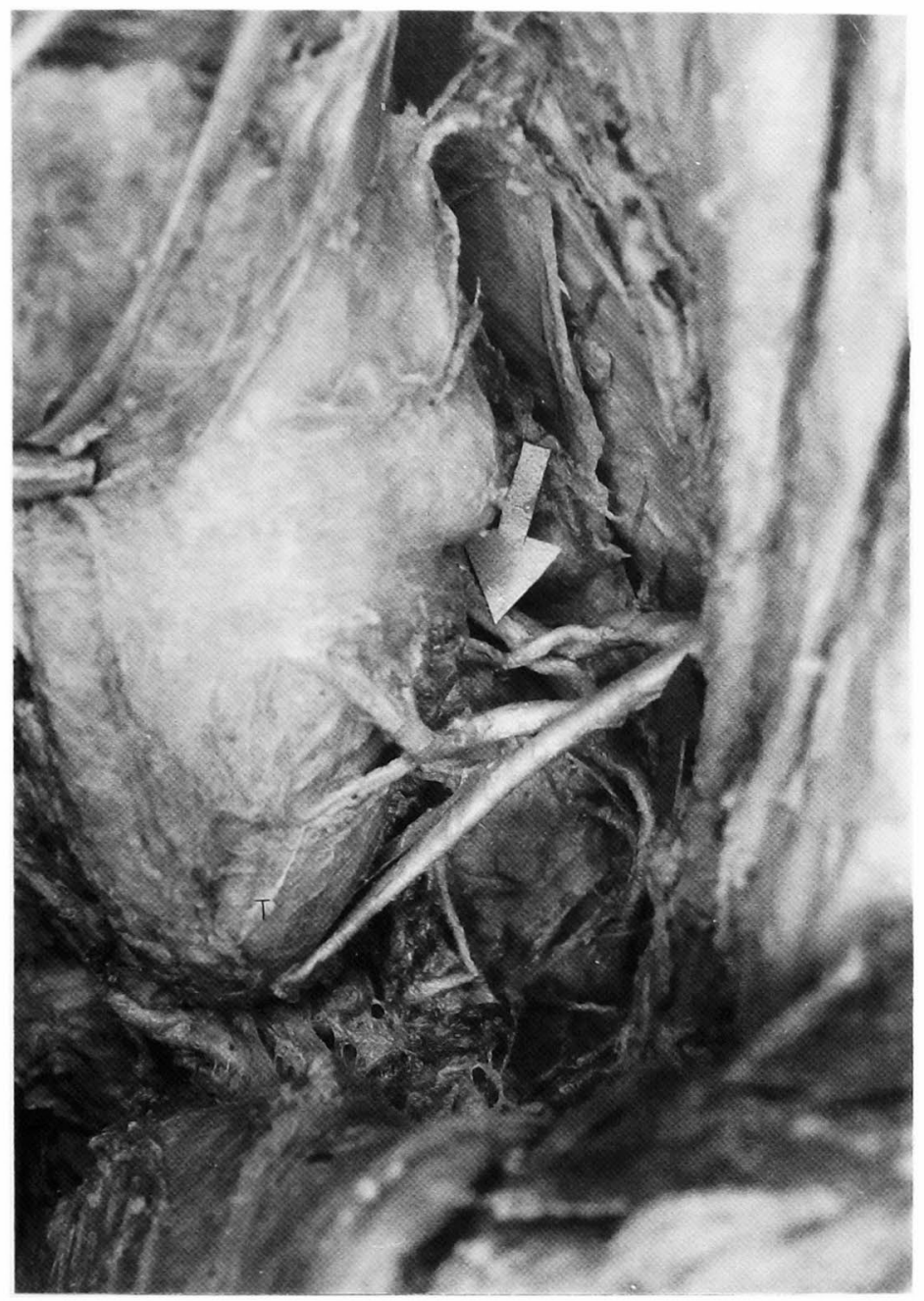

Fig. 7. The left recurrent laryngeal nerve nerve between the branches of the inferior thyroid artery (Type C). Arrow on the right: inferior thyroid artery; arrow on the left: recurrent laryngeal nerve, T: lower pole of the thyroid gland. 